\title{
Conspicuity and imaging features of breast cancers on digital breast tomosynthesis according to molecular profile
}

\section{Léa Manse}

Institut Bergonie

Martine Boisserie-Lacroix

Institut Bergonie

Véronique Brouste

Institut Bergonie

Marie-Pierre Depetiteville

Institut Bergonie

\section{Benoît Mesurolle}

Centre République Elsan

Foucauld Chamming's ( $\nabla$ f.chammings@bordeaux.unicancer.fr)

Institut Bergonie https://orcid.org/0000-0002-0397-9889

\section{Research Article}

Keywords: breast cancer, digital breast tomosynthesis, pathology, imaging features, conspicuity

Posted Date: December 6th, 2021

DOl: https://doi.org/10.21203/rs.3.rs-903353/v1

License: (1) This work is licensed under a Creative Commons Attribution 4.0 International License.

Read Full License 


\section{Abstract \\ Objective}

To describe BI-RADS features and evaluate conspicuity of breast cancer on digital breast tomosynthesis (DBT) according to their molecular profile.

\section{Materials and method}

Institutional review board was obtained for this retrospective study. Consecutive patients with histologically proven breast cancers who underwent digital breast tomosynthesis (DBT) with 2D synthetic mammography (SM) and digital mammography (DM) at the time of diagnosis were included. Morphological features and conspicuity of cancers on DM, SM and DBT were evaluated in consensus by two breast radiologists. Imaging features were compared across molecular subtypes (luminal, triple negative (TN) and HER2+) using Fisher's exact test and between DBT and SM and DM using McNemar's test. Conspicuity was compared between DBT and SM and DM using Wilcoxon matched pairs test and between each molecular subtype using the Wilcoxon test.

\section{Results}

One hundred and eleven consecutive patients were included. On DBT, TN cancers more frequently presented as masses with microlobulated margins $(P=0.04)$ while HER2 + cancers were more often associated with microcalcifications $(P=0.02)$. Greater conspicuity on DBT in comparison to DM was observed for cancers with low Ki67 $(P=.015)$, less aggressive tumours $(P=.005)$, positive ER $(P=0.005)$, positive $P R(P=.005)$ or negative HER2 $(P=.024)$, and for luminal molecular profiles $(P=0.012)$ while no difference was observed between the two techniques for TN $(P=.73)$ and HER+ $(P=.79)$ tumours.

\section{Conclusion}

DBT reveals specific features of breast cancers according to their molecular characteristics. In comparison with DM, DBT improves conspicuity of luminal subtype cancers and tumours demonstrating less aggressive features on pathology.

\section{Introduction}

According to its genetic profile, breast cancer is a heterogeneous disease with variable histological and clinical features [1]. Genetic characteristics of breast cancers are reflected by histological features such as tumor subtypes, grade, proliferation index (Ki67) and hormonal receptor expression [2]. The World Health Organization (WHO) has defined different types of cancers associated with variable prognosis according to hormonal receptor expression: Luminal, with expression of Estrogen and/or Progesterone 
receptor expression; Non-luminal HER-2+ (Human Epidermal Growth Factor Receptor-2) with no hormonal receptor expression and overexpression of HER-2; and Triple negative (TN) cancers with no hormonal receptor nor HER-2 overexpression [3]. It has been widely reported that the different subtypes of breast cancers may demonstrate specific 2D mammographic features. In particular, luminal cancers typically present as a mass with irregular shape and spiculated margins on 2D mammography, while TN cancers are more likely to demonstrate oval shape and microlobulated margins or present as asymmetries on mammography and they can mimic benign lesions [4]. In order to avoid misinterpreting such types of subtle malignant lesions in the clinical setting, it is crucial that radiologists are aware of the specific features of the different breast cancer subtypes on imaging. Although correlation between histology and imaging has been widely described previously on digital mammography (DM), specific features of breast cancers on digital breast tomosynthesis (DBT) have rarely been reported. Only one recent study

suggested that morphological features on DBT could be associated with molecular characteristics [5], but very little data are available to support this assertion. Breast cancer features on 2D synthetic mammography (SM) have not yet been reported, although it has been reported that the additional cancers detected with the adjunct of DBT in the screening setting would preferentially be less aggressive tumors with luminal molecular profiles [6, 7]. However, other recent studies found no such a difference [8, 9]. It is therefore of interest to evaluate whether molecular features have an impact on conspicuity of breast cancers on DBT, which has, to the best of our knowledge, not been evaluated previously.

The objective of this study is to evaluate whether the different molecular subtypes of invasive breast cancers are associated with specific morphological features on DBT and SM. The second objective is to evaluate the association between molecular profiles and conspicuity of breast cancers on DBT and SM in comparison with DM.

\section{Material And Methods}

\section{Study population}

IRB approval was obtained for this retrospective study and informed consent was waived.

Consecutive patients with invasive breast cancer diagnosed between March 2018 and November 2019 who underwent DBT with SM at our institution of at least the affected breast (at least one view, medio lateral oblique or cranio caudal) and a recent ( $<3$ months) DM of at least the affected breast at the time of diagnosis were eligible for inclusion. Patients were ineligible if: presence of a post-biopsy marker clip on DM or DBT/SM images, personal history of prior surgery of the ipsilateral breast and absence of invasive carcinoma in the surgical specimen.

\section{Imaging acquisition}

In our institution, DBT (Selenia dimension, Hologic, Bedford, Mass.) is routinely performed as a complementary imaging examination to DM in the diagnostic setting for characterization purposes and 
as part of the pre-treatment workup of histologically proven breast cancers. In most cases it is bilaterally in two views, in some cases unilaterally [10].

DM were performed at least for the affected breast, in at least one view [Cranio-Caudal (CC) or Medio lateral Oblique (MLO)], either at our institution or outside our institution. DM performed outside our institution were either downloaded into our local Picture Archiving and Communication System (PACS) (Entreprise Imagine ${ }^{\circledR}$, Agfa Healthcare), or reviewed on films.

\section{Image analysis}

All DBT and SM images were reviewed on dedicated workstations (Secure 3D, Hologic). DM images were either reviewed on dedicated workstations $(55 / 111)$ or on films (55/111). Two breast radiologists (*BLINDED* and *BLINDED*) with fellowship level training and respectively 20 and 14 years of experience in breast imaging and 11 and 6 years of experience in DBT, read all examinations in consensus. Readers were blinded to the molecular profile of the lesions and tumor locations. DM, SM and DBT were reviewed in three distinct reading sessions each separated by 4 weeks, to reduce potential recall bias. In situations where multiple lesions were present, instructions were given to the readers to assess the most prominent one (index tumor).

\section{Location and conspicuity}

Readers first assessed the location and conspicuity of the tumor. Conspicuity was defined as the combination of the confidence in the presence of a lesion with the confidence in decision-making based on lesion detectability. Conspicuity was assessed on the following five-point scale: 0 : no visible findings, 1: low conspicuity, 2 : medium conspicuity, 3 : high conspicuity and 4 : very high conspicuity $[11,12]$. In cases where readers determined a wrong location of the tumor (side and quadrant), conspicuity was reported as "non-visible".

\section{Characterization}

For DM and SM sessions, lesion features were assessed according to the 2013 edition of the BI-RADS lexicon [13]. Description of abnormalities on DBT is not defined in the BI-RADS lexicon. However, as routinely performed in our institution, readers were asked to describe lesions on DBT according to terms used in the fifth edition of the BI-RADS lexicon [14]. In particular, the term "mass" was assigned to lesions clearly identified and occupying a volume whereas "asymmetry" was assigned to lesions that had concave borders, contained fat or demonstrated low conspicuity. When only one view was available, no term was used for characterization of asymmetries (i.e. focal and global); and since no previous examination was available for the readers the term "developing" was not used. Finally, with each technique, readers were instructed to measure the maximum diameter of the index tumor.

\section{Pathology and assessment of tumor size}

When available, tumor sub-type, grade, HER-2 status, Estrogen and Progesterone receptors, KI67 and presence of in situ ductal carcinoma and tumor size were determined from pathology reports of the final 
surgical specimen. In patients who underwent neo-adjuvant chemotherapy (NAC) or had no surgery, tumor sub-type was determined from ultrasound-guided 14-Gauge core needle or 8-Gauge stereotacticguided vacuum-assisted biopsies. For assessment of tumor size, tumor maximum diameter on pathology of the surgical specimen was considered the gold standard. In cases of multifocal breast cancer, the maximum diameter of the largest invasive tumor (index tumor) was assessed.

\section{Statistical analysis}

Proportion of morphological features of breast cancers was compared between the different molecular profiles: Luminal, TN and HER-2 + cancers using Fisher's exact test.

Qualitiative features on each technique were compared using McNemar's test.

Conspicuity of breast cancers was compared between the different tumor subtypes, molecular characteristics, low $(<20 \%)$ and high $(>20 \%) \mathrm{Ki} 67$, and grade using the Wilcoxon test. Conspicuity between DM, SM and DBT was compared using Wilcoxon matched pairs tests. $P$ values less than 0.05 were considered statistically significant. Statistical analysis was performed using SAS V9.4 software.

\section{Results}

\section{Study population and patient characteristics}

A total of 136 patients were eligible for inclusion in our study. Thirteen patients were excluded because of presence of a post biopsy-marker clip and 6 because of history of prior surgery of the ipsilateral breast. Six patients had only in situ carcinoma on the surgical specimen and were also excluded. A total of 111 patients comprised our study population.

Mean patient age was $64 \pm 13$ years (Table 1). Seventy-eight (70\%) cancers were palpable at the time of diagnosis and 33 were not palpable (30\%). On pathology, our population consisted of 87 invasive carcinoma of non-specific type (IC-NST), 13 invasive lobular carcinomas (ILC), four mixed invasive lobular and non-specific type carcinomas, four papillary, two apocrine and one mucinous carcinomas. 
Table 1

Patient and tumour characteristics

\begin{tabular}{|c|c|c|c|c|c|}
\hline & \multicolumn{5}{|c|}{ Phenotype } \\
\hline & $\begin{array}{l}\text { Total } \mathrm{N}= \\
111\end{array}$ & $\begin{array}{l}\text { Luminal } \mathrm{N}= \\
80\end{array}$ & $\begin{array}{l}\text { HER2 } N= \\
15\end{array}$ & $\begin{array}{l}\text { TN N = } \\
13\end{array}$ & $\begin{array}{l}\text { Unclassifiable } \mathrm{N}= \\
3\end{array}$ \\
\hline Mean age $( \pm S D)$ & $64( \pm 13)$ & $66( \pm 13)$ & $52( \pm 10)$ & $65( \pm 11)$ & $63( \pm 11)$ \\
\hline Palpable & $78(63)$ & $50(62)$ & $14(93)$ & $12(92)$ & $2(67)$ \\
\hline \multicolumn{6}{|l|}{ Histology } \\
\hline Lobular & $13(12)$ & $11(14)$ & $1(7)$ & $1(8)$ & - \\
\hline Ductal & $87(78)$ & $62(78)$ & $13(87)$ & $10(77)$ & $2(67)$ \\
\hline Lobular and ductal & $4(4)$ & $3(4)$ & - & $1(8)$ & - \\
\hline Papillary & $4(4$ & $4(5)$ & - & - & - \\
\hline Apocrine & $2(2)$ & - & $1(7)$ & $1(8)$ & - \\
\hline Mucinous & $1(1)$ & - & - & - & $1(33)$ \\
\hline \multicolumn{6}{|l|}{ Grade } \\
\hline $\mathrm{N} / \mathrm{A}$ & $1(1)$ & $1(1)$ & - & - & \\
\hline 1 & $24(22)$ & $24(30)$ & - & - & - \\
\hline 2 & $59(53)$ & $47(59)$ & $8(53)$ & $2(15)$ & $2(67)$ \\
\hline 3 & $27(24)$ & $8(10)$ & $7(47)$ & $11(85)$ & $1(33)$ \\
\hline \multicolumn{6}{|l|}{ Estrogen receptor } \\
\hline $\mathrm{N} / \mathrm{A}$ & $1(1)$ & - & - & - & $1(33)$ \\
\hline No & $20(18)$ & - & $8(53)$ & $13(100)$ & $1(33)$ \\
\hline Yes & $90(81)$ & $80(100)$ & $7(47)$ & - & $1(33)$ \\
\hline \multicolumn{6}{|l|}{$\begin{array}{l}\text { Progesterone } \\
\text { receptor }\end{array}$} \\
\hline $\mathrm{N} / \mathrm{A}$ & $1(1)$ & - & - & - & $1(33)$ \\
\hline No & $29(26)$ & 9 & $8(53)$ & $13(100)$ & $1(33)$ \\
\hline Yes & $81(73)$ & 71 (89) & 7 (47) & - & 1 (33) \\
\hline HER 2 & & & & & \\
\hline
\end{tabular}




\begin{tabular}{|llllll|}
\hline \multicolumn{7}{|c|}{ Phenotype } & & & \\
\hline N/A & $1(1)$ & - & - & - & $1(33)$ \\
\hline 0 & $95(86)$ & $80(100)$ & - & $13(100)$ & $2(67)$ \\
\hline 1 & $15(13)$ & - & $15(100)$ & - & - \\
\hline KI67 & & & & & \\
\hline N/A & $1(1)$ & - & - & $1(8)$ & $1(33)$ \\
\hline$<20 \%$ & $59(53)$ & $53(66)$ & $4(27)$ & $1(8)$ & $1(33)$ \\
\hline$\geq 20 \%$ & $51(46)$ & $27(34)$ & $11(73)$ & $11(85)$ & $1(33)$ \\
\hline N/A : Non available & & & & & \\
\hline
\end{tabular}

Regarding molecular profiles, 80 cancers were luminal, 15 demonstrated overexpression of HER-2 (HER$2+)$ and 13 were triple negative (TN). Because some pathological features were not available, molecular classification could not be determined in 3 cases (HER-2 status in one case and hormonal receptors status in two); these were excluded from analysis with regard to molecular profile. Ki67 was not available for one patient. TN and HER-2 + cancers were more often palpable than luminal cancers.

\section{Imaging Features}

Imaging features of breast cancers on DM, SM and DBT according to molecular profile are presented in Tables 2, 3 and 4. Breast cancers presented as asymmetries in 32\% (36/111), 32\% (36/111) and 28\% $(31 / 111)$ of cases and as masses in $58 \%(64 / 111), 54 \%(60 / 111)$ and $64 \%(71 / 111)$ of cases on DM, SM and DBT respectively. Breast cancers more often presented as masses with spiculated margins on DBT $(50 \% ; 55 / 111)$ than on $\operatorname{DM}(33 \% ; 37 / 111)(P=0.001)$. 
Table 2

Imaging features of breast cancer according to their molecular profile on digital mammography.

\begin{tabular}{|c|c|c|c|c|}
\hline & Total $\mathrm{N}=111$ (\%) & Luminal $\mathrm{N}=80(\%)$ & HER2 $\mathrm{N}=15(\%)$ & TN N = $13(\%)$ \\
\hline Asymmetries & $36(32)$ & $28(35)$ & $3(20)$ & $3(23)$ \\
\hline Unspecified & $4(4)$ & $4(14)$ & & \\
\hline Focal & $30(27)$ & $24(186)$ & $3(20)$ & $1(8)$ \\
\hline Global & $1(1)$ & - & - & $1(8)$ \\
\hline Developing & $1(1)$ & - & - & $1(8)$ \\
\hline Mass & $64(58)$ & $43(54)$ & $11(73)$ & $9(70)$ \\
\hline \multicolumn{5}{|l|}{ Shape } \\
\hline Round & $3(3)$ & $3(4)$ & - & - \\
\hline Oval & $4(4)$ & $3(4)$ & - & $1(8)$ \\
\hline Irregular & $57(51)$ & $37(46)$ & $11(73)$ & $8(62)$ \\
\hline \multicolumn{5}{|l|}{ Margin } \\
\hline Circumscribed & $4(4)$ & $2(3)$ & $1(0.7)$ & $1(8)$ \\
\hline Microlobulated & $9(8)$ & $4(5)$ & $2(1)$ & $3(23)$ \\
\hline Obscured & $2(2)$ & $2(3)$ & - & - \\
\hline Indistinct & $12(11)$ & $7(9)$ & $2(1)$ & $3(23)$ \\
\hline Spiculated & $37(33)$ & $28(35)$ & $6(40)$ & $2(15)$ \\
\hline \multicolumn{5}{|l|}{ Density } \\
\hline Fat-containing & $1(1)$ & $1(1)$ & - & - \\
\hline Low density & $2(2)$ & $1(1)$ & $1(0.7)$ & - \\
\hline Equal density & $19(17)$ & $12(15)$ & $4(27)$ & $3(23)$ \\
\hline High density & $42(38)$ & $29(36)$ & $6(40)$ & $6(46)$ \\
\hline Distorsion & $30(27)$ & $23(29)$ & $4(27)$ & $2(15)$ \\
\hline Calcifications & $24(22)$ & $12(15)$ & $8(53)$ & $3(23)$ \\
\hline
\end{tabular}


Table 3

Imaging features of breast cancer according to their molecular profile on 2D Synthetic mammography.

\begin{tabular}{|c|c|c|c|c|}
\hline & Total $\mathrm{N}=111(\%)$ & Luminal $\mathrm{N}=80(\%)$ & HER2 N = $15(\%)$ & $\mathrm{TN} N=13(\%)$ \\
\hline Asymmetries & $36(32)$ & $25(31)$ & $4(27)$ & $5(39)$ \\
\hline Unspecified & $7(6)$ & - & - & $1(8)$ \\
\hline Focal & $29(26)$ & $25(100)$ & $4(27)$ & $4(31)$ \\
\hline Mass & $60(54)$ & $42(53)$ & $10(67)$ & $7(54)$ \\
\hline \multicolumn{5}{|l|}{ Shape } \\
\hline Round & $1(1)$ & $1(1)$ & - & - \\
\hline Oval & $3(3)$ & $2(3)$ & $1(7)$ & - \\
\hline Irregular & $56(51)$ & $39(49)$ & $9(60)$ & $7(54)$ \\
\hline \multicolumn{5}{|l|}{ Margin } \\
\hline Circumscribed & $3(3)$ & $1(1)$ & $1(7)$ & $1(8)$ \\
\hline Microlobulated & $4(4)$ & $2(3)$ & $1(7)$ & $1(8)$ \\
\hline Obscured & $1(1)$ & $1(1)$ & - & - \\
\hline Indistinct & $10(9)$ & $7(9)$ & $1(7)$ & $2(15)$ \\
\hline Spiculated & $42(38)$ & $31(39)$ & $7(47)$ & $3(23)$ \\
\hline \multicolumn{5}{|l|}{ Density } \\
\hline Low density & $1(1)$ & $1(1)$ & - & - \\
\hline Equal density & $25(23)$ & $17(21)$ & $6(40)$ & $2(15)$ \\
\hline High density & $34(31)$ & $24(30)$ & $4(27)$ & $5(39)$ \\
\hline Distorsion & $48(43)$ & $36(45)$ & $6(40)$ & $4(31)$ \\
\hline Calcifications & $23(21)$ & $13(16)$ & $7(47)$ & $3(23)$ \\
\hline
\end{tabular}


Table 4

Imaging features of breast cancer according to their molecular profile on digital breast tomosynthesis. Percentages are indicated in brackets.

\begin{tabular}{|c|c|c|c|c|}
\hline & Total $\mathbf{N}=111$ & Luminal $\mathbf{N}=\mathbf{8 0}$ & HER2 N = 15 & $\mathrm{TNN}=13$ \\
\hline Asymmetries & $31(28)$ & 24 & 3 & 3 \\
\hline Unspecified & $5(5)$ & $5(6)$ & & \\
\hline Focal & $25(23)$ & $18(23)$ & $3(20)$ & $3(23)$ \\
\hline Global & $1(1)$ & $1(1)$ & - & - \\
\hline Mass & $71(64)$ & $50(63)$ & $11(73)$ & $8(61)$ \\
\hline \multicolumn{5}{|l|}{ Shape } \\
\hline Round & $1(1)$ & $1(1)$ & - & - \\
\hline Oval & $6(5)$ & $3(4)$ & $1(7)$ & $1(8)$ \\
\hline Irregular & $63(57)$ & $44(55)$ & $10(67)$ & $7(54)$ \\
\hline unspecified & 1 & 2 & - & - \\
\hline \multicolumn{5}{|l|}{ Margin } \\
\hline Circumscribed & $3(4)$ & $2(3)$ & $1(7)$ & - \\
\hline Microlobulated & $7(6)$ & $3(4)$ & $1(7)$ & $3(23)$ \\
\hline Indistinct & $4(4)$ & $3(4)$ & - & $1(8)$ \\
\hline Spiculated & $55(50)$ & $40(50)$ & $9(60)$ & $4(31)$ \\
\hline unspecified & 2 & 2 & - & - \\
\hline \multicolumn{5}{|l|}{ Density } \\
\hline Equal density & $23(21)$ & $16(20)$ & $5(33)$ & $1(8)$ \\
\hline High density & $46(43)$ & $32(40)$ & $6(40)$ & $7(54)$ \\
\hline unspecified & 2 & 2 & - & - \\
\hline Distorsion & $68(61)$ & $54(68)$ & $8(53)$ & $6(46)$ \\
\hline Calcifications & $28(25)$ & $15(19)$ & $7(47)$ & $5(39)$ \\
\hline
\end{tabular}

Architectural distortion was present in $27 \%$ of cases (30/111) on DM, $43 \%(48 / 111)$ on SM and $61 \%$ $(68 / 111)$ on DBT. Breast cancers were more frequently associated with architectural distortion on DBT or SM than on DM $(P<.0001$ and $P=0.0004$ respectively $)$ and on DBT than on SM $(P=0.003)$. 
Breast cancers with HER-2 positive status were more frequently associated with microcalcifications than other types of cancers on all three imaging measures: DM (8/15 (53\%) vs 15/93 (16\%), $P=.003)$, SM (7/15 (47\%) vs 16/93 (17\%), $P=.01)$ and DBT (7/15 (47\%) vs 20/93 (22\%), $P=.02)$. TN tumors were more frequently described as masses with microlobulated margins $(3 / 13,23 \%)$ than other types of cancers $(4 / 95,4 \%)$ on DBT $(P=.04)$ while, when described as a mass, TN demonstrated less spiculated margins $(2 / 9,22 \%)$ than luminal cancers on DM $(28 / 42,67 \%)(P=.02)$. On DBT, we observed no significant differences of frequency of distortion according to molecular subtype $(P=.20)$

\section{Conspicuity}

Breast cancers were significantly more conspicuous on DBT than on DM $(P=0.03)$ but differences between DM and SM and SM and DBT did not reach significance ( $P=0.2$ and $P=0.25$ respectively). Eleven cancers were not visible on DM, 13 on SM and 6 on DBT. Among the eleven cancers not visible on DM, two cancers were also not visible on SM and DBT (2 ICNST grade 3, one luminal and one HER-2+).

Non-palpable breast cancers were significantly more conspicuous on DBT than on DM $(P=.02)$ whereas no differences were found for palpable cancers between the two techniques $(P=0.47)$. Cancers with low proliferation indices were less conspicuous on DM than tumors with $\mathrm{KI} 67 \geq 20 \%(P=.008)$, whereas this difference was not significant on DBT $(P=.11)$.

With respect to pathological features, better conspicuity on DBT compared to DM was observed for breast cancers with low proliferation index (Ki67 $\leq 20 \%)(P=.015)$, less aggressive tumors (grade 1 or 2$)$ $(P=.005)$, cancers with positive ER $(P=.005)$, positive PR $(P=.005)$ or negative HER-2 $(P=.024)$, and cancers with luminal molecular profiles $(P=.012)$. On the contrary, no significant differences were observed between the two techniques for cancers with high proliferation indices (Ki67 $\geq 20 \%)(P=.76)$; grade $3(P=.75)$; negative $\mathrm{ER}(P=.33)$, negative PR $(P=.56)$ or positive HER-2 tumors $(P=.79)$ and for triple negative tumors $(P=.73)$.

\section{Discussion}

Our results show that breast cancers may demonstrate different features on DBT than on DM. In particular, cancer more often demonstrates architectural distortion on DBT. Moreover, we showed that according to their molecular profile, breast cancers could demonstrate specific features on DBT and on SM. In our study, TN breast cancers more frequently presented as masses with microlobulated margins on DBT and, like on DM, HER-2 positive tumors more frequently demonstrated microcalcifications on DBT and on SM. We also observed that conspicuity of luminal breast cancers was better on DBT than on DM while conspicuity of HER-2 + or TN tumors was not significantly improved.

Breast cancer is a clinically, histologically and molecularly heterogeneous disease with variable prognosis. It is now well established that according to their histological features, breast cancers may demonstrate different morphological features on digital mammography. Hence, it has been reported that luminal subtype breast tumors more likely present as spiculated masses than triple negative cancers [15]. 
It has also been observed that HER-2 + tumors were more frequently associated with microcalcifications on DM than other subtypes [16]. Being aware of the specific features of the different histological types of breast cancers on imaging is of great importance in clinical practice. In particular, knowing that some cancers can more often demonstrate less suspicious features on DBT, such as microlobulated margins for TN tumors, may incite breast radiologists to pay particular attention when diagnosing a breast lesion with such characteristics. Moreover, at the time when more and more publications suggest that mathematical parameters derived from radiomic analysis of breast cancers might be interesting biomarkers of cancer aggressiveness and prognosis, it is of interest to show that tumor morphological features on a recent technique such as DBT may also reflect the underlying pathology [17-19].

Since it is a relatively recent technique, specific features of breast cancers on DBT have indeed been scarcely described. To the best of our knowledge, only one study evaluated the appearance of breast cancers on DBT according to their histology and molecular profile [5]. In line with our results, they showed that presence of calcifications within the tumors on DBT was more frequent in HER-2 + than in other types of breast cancers. However, our study is the first to show that triple-negative tumors may also demonstrate specific feature on DBT i.e. presenting more frequently as masses with microlobulated margins than other cancers. Moreover, we also showed that DBT could predominantly improve conspicuity of less aggressive breast cancers. Improvement of conspicuity of breast cancers on DBT has also been shown to vary according to pathology and was more pronounced for lobular than for ductal invasive carcinomas [12]. Although we could not demonstrate such a difference in our study, probably because of the relatively small number of lobular carcinomas in our population, our finding are in line with previous publications, suggesting that additional breast cancers detected on DBT would be more predominantly luminal subtypes and low-grade tumors $[7,20]$. This increased detection of luminal subtypes cancers on DBT compared to DM might be due to their specific features, i.e. more frequent spiculated margins, that are known to be particularly well visualized on tomosynthesis [21]. In this context, our study provides interesting results with regards to the histological features of breast cancers underlying their conspicuity on DBT in comparison with DM.

Our study has some limits. First it is a retrospective study with a relatively small sample size, in particular for the number of TN and HER-2 + tumors. Secondly, in our study TN and HER-2 + were more often palpable that luminal cancers and we did not evaluate whether better conspicuity on DM was due to bigger tumor size or to specific morphological features on imaging. Further studies including more cases of TN and HER-2 + breast cancers would be needed to determine whether specific features on imaging are independent factors of better conspicuity of breast tumors on DBT. Finally, $50 \%$ of DM cases were reviewed on films and not on the dedicated workstation which could have altered conspicuity and characterization assessments with DM, although some publications reported that soft-copy reading provides no advantage for interpretation [22, 23].

\section{Conclusion}


We showed that breast cancers may demonstrate specific features on DBT according to their molecular features. Our result suggest that DBT may predominantly improves the conspicuity of less aggressive tumors, which would benefit the most from an increased detection rate with the use of DBT.

\section{Declarations}

\section{Acknowledgements}

The authors thank Pippa McKelvie-Sebileau for medical editing in English.

\section{Funding}

The authors state that this work has not received any funding.

\section{Conflict of interest}

F. Chamming's is a speaker for Hologic, Supersoniclmagine, Devicor Medical.

The other authors have no conflict of interest.

\section{Authors' contributions}

L. Manse: Conceptualization, Data curation, Investigation, Methodology, Writing - original draft, Writing review \& editing.

M. Boisserie-Lacroix: Conceptualization, Data curation, Investigation, Writing - review \& editing.

V. Brouste: Conceptualization, Formal analysis, Methodology, Writing - review \& editing.

M.P. Depetiteville: Conceptualization, Investigation, Writing - review \& editing.

B. Mesurolle: Conceptualization, Methodology, Writing - review \& editing.

F. Chamming's: Conceptualization, Data curation, Formal analysis, Investigation, Methodology, Supervision, Validation, Writing - original draft, Writing - review \& editing.

\section{References}

1. Perou CM, Sørlie T, Eisen MB, van de Rijn M, Jeffrey SS, Rees CA, et al. (2000) Molecular portraits of human breast tumours. Nature 406(6797):747-752.

2. Rakha EA, Reis-Filho JS, Ellis IO (2010) Combinatorial biomarker expression in breast cancer. Breast Cancer Res Treat 120(2):293-308. 
3. Tan PH, Ellis I, Allison K, Brogi E, Fox SB, Lakhani S, et al. (2020) The 2019 World Health Organization classification of tumours of the breast. Histopathology 77(2):181-185.

4. Lamb PM, Perry NM, Vinnicombe SJ, Wells CA (2000) Correlation between ultrasound characteristics, mammographic findings and histological grade in patients with invasive ductal carcinoma of the breast. Clin Radiol 55(1):40-44.

5. Cai S, Yao M, Cai D, Yan J, Huang M, Yan L, et al (2019) Association between digital breast tomosynthesis and molecular subtypes of breast cancer. Oncol Lett 17(3):2669-2676.

6. Kim JY, Kang HJ, Shin JK, Lee NK, Song YS, Nam KJ, et al. (2017) Biologic profiles of invasive breast cancers detected only with digital breast tomosynthesis. AJR Am J Roentgenol 209(6):14111418.

7. Caumo F, Romanucci G, Hunter K, Zorzi M, Brunelli S, Macaskill P, et al. (2018) Comparison of breast cancers detected in the Verona screening program following transition to digital breast tomosynthesis screening with cancers detected at digital mammography screening. Breast Cancer Res Treat 170(2):391-397.

8. Bahl M, Gaffney S, McCarthy AM, Lowry KP, Dang PA, Lehman CD (2017) Breast cancer characteristics associated with 2D digital mammography versus digital breast tomosynthesis for screening-detected and interval cancers. Radiology 287(1):49-57.

9. Hovda T, Holen ÅS, Lång K, Albertsen JL, Bjørndal H, Brandal SHB, et al. (2020) Interval and consecutive round breast cancer after digital breast tomosynthesis and synthetic 2D mammography versus standard 2D digital mammography in BreastScreen Norway. Radiology 294(2):256-264.

10. Fontaine M, Tourasse C, Pages E, Laurent N, Laffargue G, Millet I, et al. (2019) Local tumor staging of breast cancer: digital mammography versus digital mammography plus tomosynthesis. Radiology 291(3):594-603.

11. Gennaro G, Toledano A, di Maggio C, Baldan E, Bezzon E, La Grassa M, et al. (2010) Digital breast tomosynthesis versus digital mammography: a clinical performance study. Eur Radiol 20(7):1545-1553.

12. Chamming's F, Kao E, Aldis A, Ferré R, Omeroglu A, Reinhold C, et al. (2017) Imaging features and conspicuity of invasive lobular carcinomas on digital breast tomosynthesis. $\mathrm{Br} \mathrm{J}$ Radiol 90(1073):20170128.

13. D'Orsi C (2003) Breast imaging reporting and data system: ACR BI-RADS-mammography (4 ${ }^{\text {th }}$ ed). Reston VA: American College of Radiology.

14. Andersson I, Ikeda DM, Zackrisson S, Ruschin M, Svahn T, Timberg P, et al. (2008) Breast tomosynthesis and digital mammography: a comparison of breast cancer visibility and BIRADS 
classification in a population of cancers with subtle mammographic findings. Eur Radiol 18(12):28172825.

15. Taneja S, Evans AJ, Rakha EA, Green AR, Ball G, Ellis IO (2008) The mammographic correlations of a new immunohistochemical classification of invasive breast cancer. Clin Radiol 63(11):1228-1235.

16. Shin HJ, Kim HH, Huh MO, Kim MJ, Yi A, Kim H, et al. (2011) Correlation between mammographic and sonographic findings and prognostic factors in patients with node-negative invasive breast cancer. $\mathrm{Br}$ J Radiol 84(997):19-30.

17. Tagliafico AS, Bignotti B, Rossi F, Matos J, Calabrese M, Valdora F, et al. (2019) Breast cancer Ki-67 expression prediction by digital breast tomosynthesis radiomics features. Eur Radiol Exp 3(1):36.

18. Geras KJ, Mann RM, Moy L (2019) Artificial intelligence for mammography and digital Breast tomosynthesis: current concepts and future perspectives. Radiology 293(2):246-259.

19. Son J, Lee SE, Kim E-K, Kim S (2020) Prediction of breast cancer molecular subtypes using radiomics signatures of synthetic mammography from digital breast tomosynthesis. Sci Rep 10(1):21566.

20. Yun SJ, Ryu C-W, Rhee SJ, Ryu JK, Oh JY (2017) Benefit of adding digital breast tomosynthesis to digital mammography for breast cancer screening focused on cancer characteristics: a meta-analysis. Breast Cancer Res Treat 164(3):557-569.

21. Hofvind S, Hovda T, Holen ÅS, Lee Cl, Albertsen J, Bjørndal H, et al. (2018) Digital breast tomosynthesis and synthetic 2D mammography versus digital mammography: evaluation in a population-based screening program. Radiology 287(3):787-794.

22. Funke M, Obenauer S, Hermann KP, Fischer U, Grabbe E (2002) [Soft copy versus hard copy findings in digital mammography]. Radiologe 42(4):265-269.

23. Nishikawa RM, Acharyya S, Gatsonis C, Pisano ED, Cole EB, Marques HS, et al. (2009) Comparison of soft-copy and hard-copy reading for full-field digital mammography. Radiology 251(1):41-49.

\section{Figures}



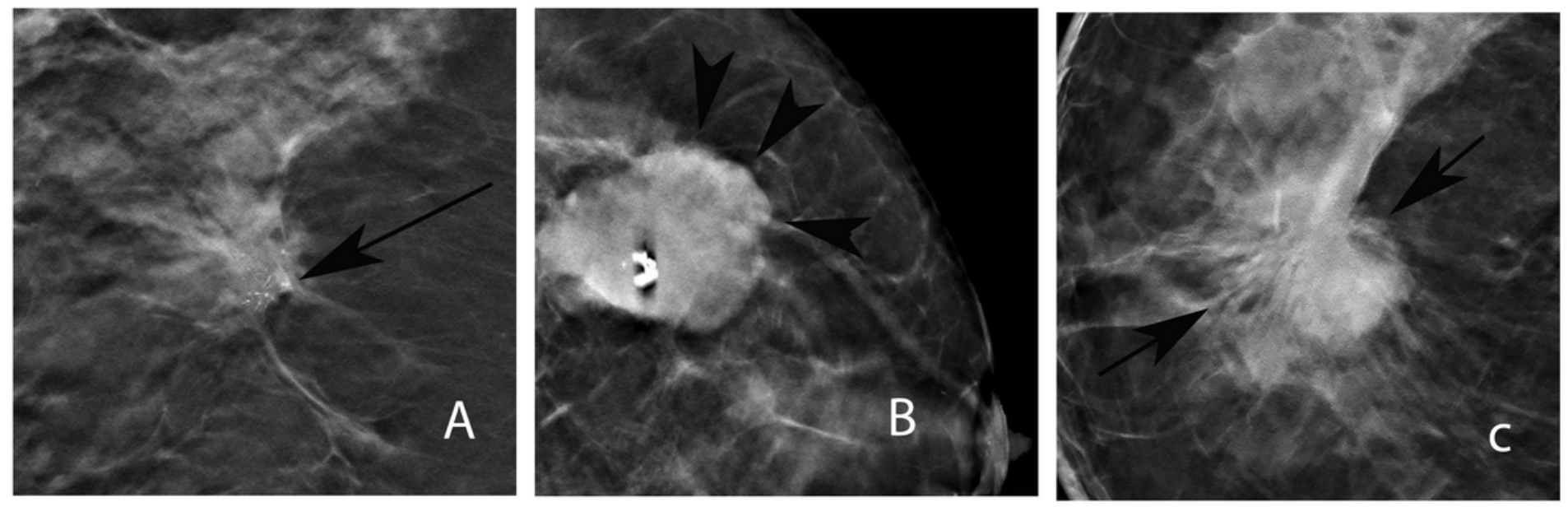

\section{Figure 1}

Imaging features of breast cancer on DBT according to molecular sub-type: (A) 54-year-old woman with invasive carcinoma of non-specific type HER-2+ of the right breast, presenting as a mass with microcalcifications; (B) 62-year-old woman with triple negative invasive carcinoma of non-specific type of the right breast, presenting as a mass with microlobulated margins; (C) 69-year-old woman with invasive carcinoma of non-specific type of the right breast luminal B, presenting as a mass with spiculated margins.
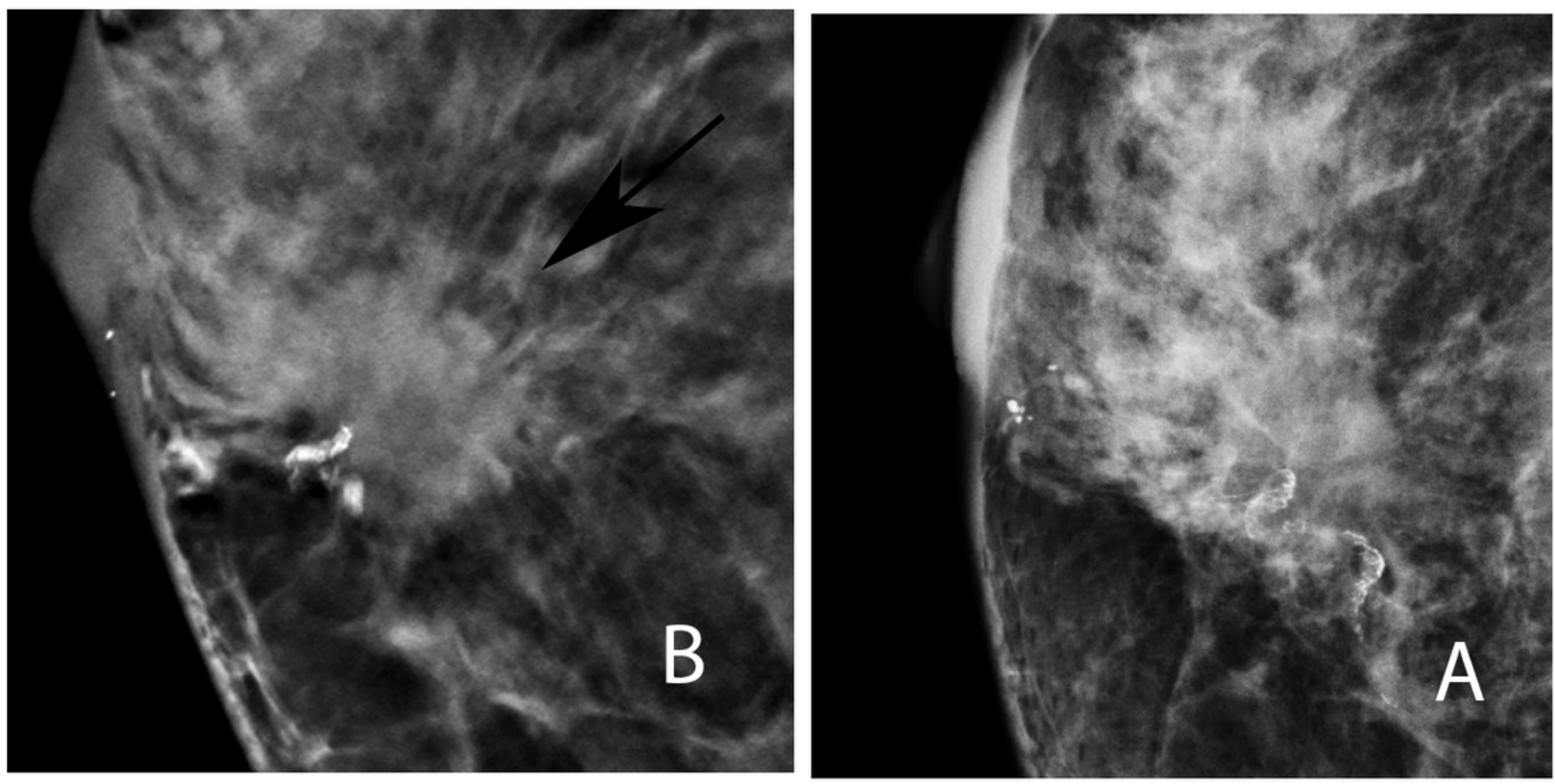

\section{Figure 2}

Improvement of conspicuity of breast cancer on digital breast tomosynthesis (DBT) versus digital mammography (DM): 63-year-old woman with a non-palpable invasive carcinoma of non-specific type, 
with luminal A. (A) On DM the tumor is described as non visible. (B) On DBT, the cancer is well visualized as a mass with spiculated margins with conspicuity described as very high. 